\title{
The Influence of Molding Pressure on the Mechanical Properties of Aluminum Borate Whisker Reinforced Aluminum Phosphate Composite Materials
}

\author{
Zhen-Yu LV ${ }^{a^{*}}$ \\ Shandong Polytechnic, Jinan, Shandong, China \\ alvzhy517@sina.com \\ Corresponding author
}

Keywords: Composite Materials, Wave-transparent Material, Molding Pressure, Mechanical Property.

\begin{abstract}
Choose the aluminum borate whisker (40wt\%) reinforced aluminum phosphate composite material, molding under the pressure of $100 \mathrm{MPa}$ and $200 \mathrm{MPa}$, and sintered at $1050^{\circ} \mathrm{C}, 1100^{\circ} \mathrm{C}, 1150^{\circ} \mathrm{C}$, $1200^{\circ} \mathrm{C}, 1250^{\circ} \mathrm{C}, 1300^{\circ} \mathrm{C}, 1350^{\circ} \mathrm{C}$, then test the flexural strength, Vickers hardness and fracture toughness of composites. The results show that the flexural strength, Vickers hardness and fracture toughness of the sample increase first and then decrease with the increase of sintering temperature; at the same sintering temperature, the mechanical properties of the sample under $200 \mathrm{MPa}$ are better than that of the sample under 100MPa.
\end{abstract}

\section{Introduction}

For the composites prepared by pressureless sintering process, the molding pressure has very important influence on the mechanical properties of the composite [1]. A certain pressure must be exerted for powder molding; the suitable molding pressure can improve green density and create conditions in intimate contact between the particles for sintering, so that the diffusion resistance is reduced during sintering. Usually green density and densification degree of sintered is proportional. In general, the greater the pressure molding, the closer contact between the particles, the more favorable the sintering. However, if the pressure is too large, the plastic deformation of powder will over the limit, so that the green strength is insufficient make brittle fracture [2].

\section{The Influence of Molding Pressure on the Flexural Strength of Composite Materials}

Tab. 1 shows the effects of sintering temperature and forming pressure on flexural strength. The relation of sintering temperature and forming pressure with flexural strength of composites is shown in Fig. 1.

Tab. 1 Effects of sintering temperature and forming pressure on flexural strength (MPa)

\begin{tabular}{cccccccc}
\hline Molding & \multicolumn{7}{c}{ Sintering Temperature $\left({ }^{\circ} \mathrm{C}\right)$} \\
\cline { 2 - 8 } Pressure (Mpa) & 1050 & 1100 & 1150 & 1200 & 1250 & 1300 & 1350 \\
\hline 100 & & 44.50 & 76.15 & 140.97 & 186.32 & 170.84 & 158.51 \\
200 & 137.78 & 182.25 & 215.79 & 231.35 & 218.59 & 207.78 & \\
\hline
\end{tabular}

It can be seen from Fig. 1, the bending strength variation of the sample molding under $200 \mathrm{MPa}$ and molding under $100 \mathrm{Mpa}$ is the same, which first increases and then decreases. However, the sintering temperature that reaches the maximum bending strength is not the same, which is $1200^{\circ} \mathrm{C}$ and $1250^{\circ} \mathrm{C}$ respectively. At the same sintering temperature, with the increase of the forming pressure, the bending strength of the sample also will be improved to some extent. This is because when the molding pressure increases, inside the green body, the arrangement between the substrate and the substrate and between the substrate and the whiskers are more closely, the porosity content of the green body reduced. This facilitates the matrix plastic flow under external force, which contribute to rearrange between the phase 


\section{ATLANTIS
PRESS}

particles and whiskers, and the sample can be achieved complete sintering at lower temperatures, densification, and improved the bending strength of the composite [3].

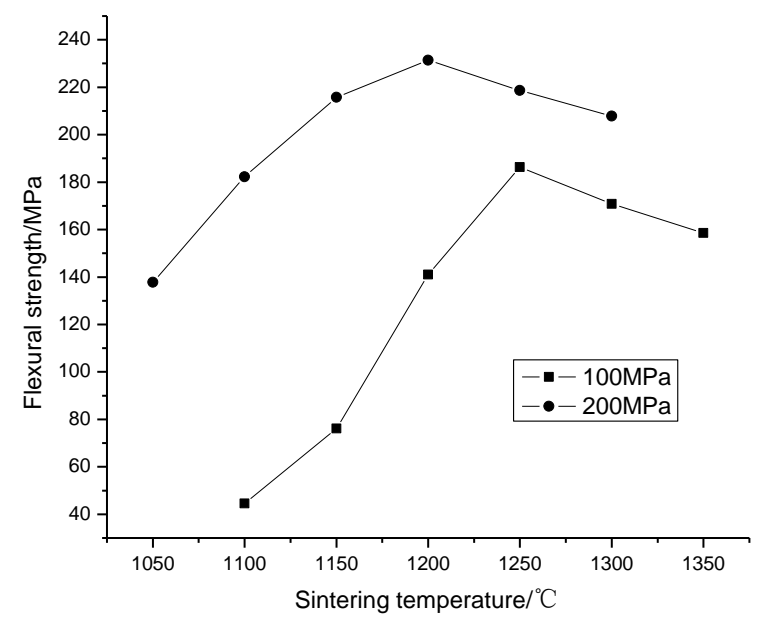

Fig. 1 Relation of sintering temperature and forming pressure with flexural strength of composites

Fig. 2 shows the SEM micrograph of fracture section of the sample with $40 \mathrm{wt} \%$ whisker at $1200^{\circ} \mathrm{C}$. It can be seen from the Fig. 3, the sample molding under 100MP has large pores and its organizational structure is loose; but the sample molding under 200MP has a few pores and its organizational structure is compact.

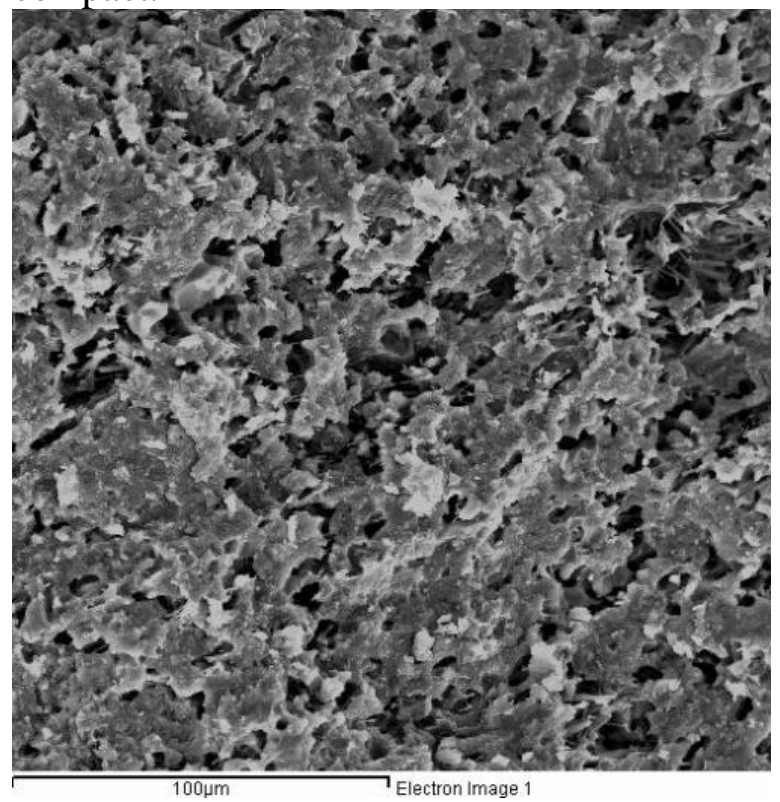

(a) Molding pressure $100 \mathrm{MPa}$

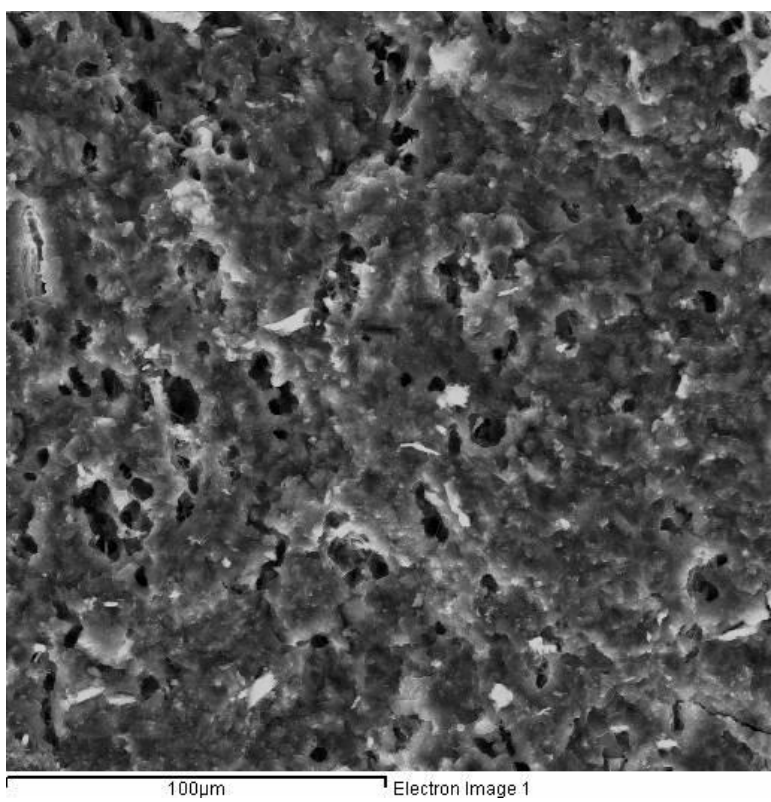

(b) Molding pressure $200 \mathrm{MPa}$

Fig.2 SEM micrograph of fracture section of $40 \mathrm{wt} \%$

Analysis result shows that when the sample with $40 \mathrm{wt} \%$ whisker forming under the pressure of $100 \mathrm{MPa}$ was sintered at $1250^{\circ} \mathrm{C}$, its maximum bending strength was $186.32 \mathrm{MPa}$; and when the sample with $40 \mathrm{wt} \%$ whisker forming under the pressure of $200 \mathrm{MPa}$ was sintered at $1200^{\circ} \mathrm{C}$, its maximum bending strength was $231.35 \mathrm{MPa}$.

\section{The Influence of Molding Pressure on the Vickers Hardness of Composite Materials}

Tab. 2 shows the effects of sintering temperature and forming pressure on Vickers hardness of composites. The relation of sintering temperature and forming pressure with Vickers hardness of composites is shown in Fig. 3. 
Tab. 2 Effects of sintering temperature and forming pressure on Vickers hardness of composites (MPa)

\begin{tabular}{|c|c|c|c|c|c|c|c|}
\hline \multirow{2}{*}{$\begin{array}{c}\text { Molding } \\
\text { Pressure (Mpa) }\end{array}$} & \multicolumn{7}{|c|}{ Sintering Temperature $\left({ }^{\circ} \mathrm{C}\right)$} \\
\hline & 1050 & 1100 & 1150 & 1200 & 1250 & 1300 & 1350 \\
\hline 100 & & 96.13 & 106.08 & 152.23 & 178.53 & 264.4 & 253.12 \\
\hline 200 & 188.66 & 212.01 & 279.85 & 308.06 & 283.39 & 273.37 & \\
\hline
\end{tabular}

It can be seen from Fig. 3, the Vickers hardness variation of the sample molding under 200MPa and molding under $100 \mathrm{Mpa}$ is the same, which first increases and then decreases. However, the sintering temperature that reaches the maximum Vickers hardness is not the same, which is $1200^{\circ} \mathrm{C}$ and $1300^{\circ} \mathrm{C}$ respectively. It can also be seen from Figure 4, at the same sintering temperature, with the increase of the molding pressure, the Vickers hardness of the sample also will be improved to some extent. When the sample forming under the pressure of $200 \mathrm{MPa}$ was sintered at $1200^{\circ} \mathrm{C}$, its maximum Vickers hardness was $308.06 \mathrm{MPa}$. These variations are also due to increase sample molding pressure, so that the porosity and the relative density of the sample have changed [4].

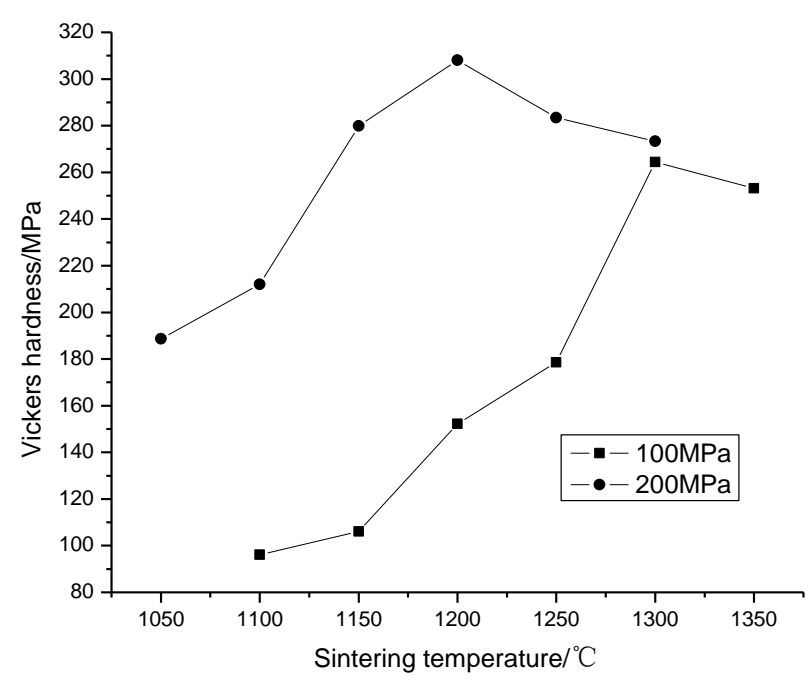

Fig. 3 Relation of sintering temperature and forming pressure with Vickers hardness of composites

\section{The Influence of Molding Pressure on the Fracture Toughness of Composite Materials}

Tab. 3 shows the effects of sintering temperature and forming pressure on fracture toughness of composites. The relation of sintering temperature and forming pressure with fracture toughness of composites is shown in Figure 4

Tab. 3 Effects of sintering temperature and forming pressure on fracture toughness of composites $\left(\mathrm{MPa} \bullet \mathrm{m}^{1 / 2}\right)$

\begin{tabular}{|c|c|c|c|c|c|c|c|}
\hline \multirow{2}{*}{$\begin{array}{c}\text { Molding } \\
\text { Pressure (Mpa) }\end{array}$} & \multicolumn{7}{|c|}{ Sintering Temperature $\left({ }^{\circ} \mathrm{C}\right)$} \\
\hline & 1050 & 1100 & 1150 & 1200 & 1250 & 1300 & 1350 \\
\hline 100 & & 1.67 & 1.82 & 2.21 & 2.91 & 3.86 & 3.64 \\
\hline 200 & 2.01 & 2.17 & 2.71 & 3.01 & 4.2 & 4.04 & \\
\hline
\end{tabular}




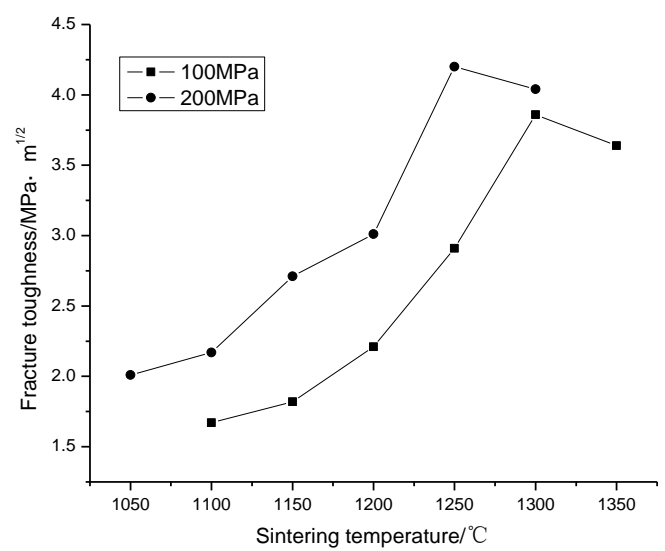

Fig. 4 Relation of sintering temperature and fracture toughness at different forming pressure

It can be seen from Figure 4, the fracture toughness variation of the sample under different pressures molded is the same, which first increases and then decreases. And at the same sintering temperature, with the increase of the molding pressure, the fracture toughness also will be improved to some extent, but the level of increase is not great. Although increasing the molding pressure can make the combination between matrix and whisker more tightly and make the interface between the matrix and the whiskers more firmly, crack propagation becomes easier. This is because after the molding pressure is increased, porosity of the sample decreases, the density increase, microscopic defects reduce, the possibility that cracks encountered defects in the course of extending are reduced, so that energy consumption reduces [5]. When the sample with $40 \mathrm{wt} \%$ whisker forming under the pressure of $100 \mathrm{MPa}$ was sintered at $1300^{\circ} \mathrm{C}$, its maximum fracture toughness was $3.86 \mathrm{MPa}^{1 / 2} \mathrm{~m}^{1 / 2}$; and when the sample with $40 \mathrm{wt} \%$ whisker forming under the pressure of $200 \mathrm{MPa}$ was sintered at $1250^{\circ} \mathrm{C}$, its maximum fracture toughness was $4.2 \mathrm{MPa} \cdot \mathrm{m}^{1 / 2}$.

\section{Summary}

In the test, when the forming pressure was $200 \mathrm{MPa}$, the sample was hard to demould, and fractured at the edge of the green body. Further, Compared to the sample molding pressure under 200MPa and molding pressure under $100 \mathrm{MPa}$, the porosity and relative density are improved, but the level of increase is not great. Compared with the sample containing 30wt\% whisker and molded under pressure $100 \mathrm{MPa}$, the performance indicators is similar and has stabilized. This shows that $100 \mathrm{MPa}$ molding pressure can satisfy the molding requirements of aluminum borate whisker - aluminum phosphate composite material. The molding pressure is more, the porosity is smaller, it will also increase the dielectric constant of the composite material to reduce dielectric properties. Therefore, this experiment chose $100 \mathrm{MPa}$ as aluminum borate whisker - aluminum phosphate composite molding pressure.

\section{References}

[1] Lin Guangyong, Lei Tingquan, Zhou Yu, Evaluation Method of Fracture Toughness of Ceramic Materials, Aerospace Materials \& Technology. 4 (1995) 12-19.

[2] Zhou Yu, Ceramic Materials Science, Harbin Institute of Technology Press, Harbin, 1995.

[3] Ke Qinqin, Cheng Laifei, Tong Qiaoying, Joining Methods for Continuous Fiber Reinforced Ceramic Matrix Composites, Journal of Materials Engineering. 11 (2005) 58-63.

[4] Xiang Yibin, Chen Dunjun, Wu Shichun, Toughening Mechanics Mechanism and Toughening Design for Material Interfaces, Journal of Materials Engineering. 7 (2000) 10-12.

[5] Guan Zhenduo, Zhang Zhongtai, Jiao Jinsheng, The Physical Properties of Inorganic Materials, Tsinghua University Press, Beijing, 1992. 